\title{
Social Network Sites for Engineers: A Necessary Distraction? ${ }^{1}$
}

\author{
Tara Mawhinney, MLIS \\ Liaison Librarian, \\ Schulich Library of Science and Engineering \\ McGill University \\ tara.mawhinney@mcgill.ca
}

${ }^{1}$ Thank you to Deena Yanofsky for her valuable contributions to this paper.

\begin{abstract}
Web 2.0 technologies and the emergence of social network sites have changed the speed and interfaces through which research is conducted, making collaboration and sharing easier and more intuitive than ever before. Facebook-style services aimed at engineers offer new ways to rapidly identify potential collaborators solve specific problems and build networks of like-minded individuals. Given the widespread adoption of these new tools, this paper explores some of the main features of these Web 2.0 technologies with regard to information literacy competencies and the role of the librarian in ensuring students are prepared for the processes of knowledge retrieval and decision-making, skills which characterize the information literate engineer.
\end{abstract}

\section{Introduction}

Typified by websites like Facebook, LinkedIn, MySpace and Twitter, social network sites are often seen as frivolous distractions, applications that represent all that is trivial and irrelevant about the Web 2.0 concept. More and more, however, internet users are recognizing the benefits of social network sites and the power of these tools to transform online communication. Incorporating Web 2.0 technologies such as wikis, blogs, tagging and social bookmarking, internet-facilitated social networks are emerging as both powerful information resources and innovative tools for professional practice. Engineering information is no exception; there are several initiatives from publishers, professional associations and commercial enterprises that support socialcomputing platforms for engineers. This new wave of technology offers engineers new methods to share their knowledge and expertise, extending collaboration, user-generated content sharing and knowledge management techniques, activities which complement modern engineering practices.

The aim of this paper is to explore the potential of social network sites in engineering practice, linking the benefits associated with electronic social networking to the information skills required for successful lifelong learning.

\section{Background}

Engineering is an industry very much dependent on the successful transfer of information. Engineers spend more than half their time processing, communicating and disseminating information [1], a process that is vital to the successful design, implementation, and marketing of products and software systems - activities that are inherently collaborative. In recent years, online social networks have made these interactions and collaborations more flexible and fluid, changing the way engineers work. Engineering firms in aerospace, defence, and automotive industries, for example, are adopting social networking as business tools, leveraging the power of Web 2.0 to find new business opportunities, new communities of like-minded individuals, and new sources of industry-specific wisdom, advice and expertise [2]. These changes are happening, industry writer Leslie Gordon points out, even though many engineers think social computing is just a distraction [3].

The essence of Web 2.0 technologies is collaborative information creation and retrieval. Social software allows users to participate in two-way conversations in which all participants have the opportunity to contribute and share opinions and knowledge. Although these virtual activities closely emulate the collaboration that has always been vital to engineering research and innovation, Web 2.0 
technologies also provide users with the ability to act together to build knowledge bases that fit their needs at different times in different ways.

Tim O'Reilly first introduced the term Web 2.0 in 2004 to describe these "architectures of participation," systems of feedback that get better the more people use them [4]. With Web 2.0, the community's contributions are central: networking sites exist only to create and serve those contributions. The result is a bottom-up rather than top-down classification of information. Social technologies like blogs, wikis and collaborative bookmarking support increasingly unstructured, nonlinear user-generated content; information is created and recreated in ways that are significant to users at different times in different formats. These changes to the characteristics of information increase the need for higher-level evaluation and analysis skills [5] — essential thinking skills which characterize the information literate engineer.

To date, research studies on the adoption of social networking tools and the unique challenges they create for users in identifying, evaluating, acquiring and using information is quite limited. Industry publications and the popular press discuss the benefits and risks of social networking for engineers, but these articles largely focus on issues such as quality control, security, and privacy for large organizations [4]. Where research does exist, mainly in the fields of education and information science, much has focussed on the adoption of Web 2.0 technologies to teach information literacy skills but little has focussed specifically on social network sites [6]. This is not the first paper to map information literacy skills to these new technologies [5] [7] - though no other papers have looked specifically at engineers and social networking technologies within the framework of information literacy. The fact that a significant number of individuals have already adopted these technologies in the management of their social and professional lives suggests that there is a strong need for research and education that focuses specifically on the skills users require to effectively use these technologies for information-defined practices.

\section{The Information Literate Engineer}

Engineering is defined as the creation or improvement of designs, products and processes. As such, it encompasses both intellectual and physical tasks (i.e., both knowing and doing) [8]. Several studies on the different types of intellectual behaviours in which engineers engage found that 40 to $66 \%$ of their working time is spent processing, communicating, and disseminating information [1] [9]. These studies focused on traditional communication channels where information is communicated top-down or in one direction.

The increased presence of diverse sources of information in all spheres of personal and professional life has led to a situation in which the skills needed to handle and manage information has become an increasingly vital element in higher education and in the development of society in general [7]. This is why the Association of College and Research Libraries (ACRL) developed Information Literacy Competency Standards for Higher Education, commonly known as the Information Literacy Standards [10]. The ACRL claims that "To be information literate, a person must be able to recognize when information is needed and have the ability to locate, evaluate, and use effectively the needed information" [11]. These standards guide educators in helping students build the higher-order thinking skills related to the organization, evaluation and management of information. They provide the backbone to the work of many academic librarians and educators today.

Information Literacy Standards for Science and Technology grew out of the needs specific to the disciplines of science and engineering. In 2006 the ACRL identified specific performance indicators that are accompanied by one or more outcomes for assessing the progress toward information literacy of students of science and technology at all levels of higher education. These standards are:

1. The information literate student determines the nature and extent of the information needed.

2. The information literate student acquires needed information effectively and efficiently

3. The information literate student critically evaluates the procured information and its sources, and as a result, decides whether or not to modify the initial query and/or seek additional sources and whether to develop a new research process.

4. The information literate student understands the economic, ethical, legal, and social issues surrounding the use of information and its technologies and either as an individual or as a member of a group, uses information effectively, ethically, and legally to accomplish a specific purpose.

5. The information literate student understands that information literacy is an ongoing process and an important component of lifelong learning and recognizes the need to keep current regarding new developments in his or her field. [12]

The above standards reflect a growing recognition not only of the importance of lifelong learning, but 
also the need for promotion and education of critical thinking skills that support the use of knowledge throughout a person's life.

\section{Integrating Web 2.0 in IL Instruction}

Not surprisingly, given the prevalence of Web 2.0 technologies, many librarians and educators have adopted these tools into their professional practices. Many libraries, for example, use social network sites for marketing and promotion of library services [13]. Other educators are adopting Web 2.0 tools in their classrooms. Facebook is often used as an informal educational network to help students connect with other students to organize group meetings for academic project work, revision and coursework queries [14].

More recently, educators concerned with (or responsible for) information literacy have begun to examine social network sites for teaching and learning. Librarians and educators have been using social technologies in several different ways. Many have been teaching the use of the technologies themselves to support teaching and learning. Others have been using social technologies to teach more general concepts, as a way of reaching students by using technologies with which they are already familiar to teach more general concepts of library science information organization. For example, Luo reports on studies where educators use "Flickr to ease students into the learning of database searching" [6]. Others have been addressing specific issues raised by these technologies such as their ethical use, privacy, collaboration, critical-thinking, etc. [5] [7].

\section{Social Network Sites: A Necessary Distraction}

Social network sites are a necessary distraction for the engineering professional; these tools (1) are efficient for information-gathering, enabling users to access different types of information from a variety of different channels, and (2) encourage engineers to incorporate higher-order thinking skills into their practice, an essential mark of the information literate professional.

Social network sites provide a single platform for information gathering because they combine the advantages of searching for information from both human and online sources. Robinson's research into the information-seeking behaviour of engineers demonstrates that although engineers find it "more efficient to use other people as information sources," they readily seek information from online sources as well [1]. This makes them likely candidates for adopting online tools such as social network sites for their work. In other words, because social network sites combine the advantages of both human and online sources to facilitate information gathering, they enable the engineer to do his or her work as he or she is used to, only more efficiently.

Social network sites also encourage the behaviours that all information literate engineers should be engaged in. They enable engineers to incorporate the higher-order thinking skills outlined in the standards which include validating one's understanding through group discussion and seeking expert opinion through a variety of mechanisms such as interviews, listservs, etc. [12]. As Jones notes, they also foster the skills needed for collaboration and creation: "[social] technologies...allow for input and contribution to these evolving ideas, building evaluation and creation skills in learners - [all] of which are essential higher-order thinking skills important to information literacy" [5]. Many of these information literacy competencies can be developed through use of social network sites, which facilitate group discussion and collaboration. The following section will examine how social network sites foster these competencies.

\section{Evaluation: SNSs, IL and Engineers}

Over the past few years, a growing number of social network sites have been developed with scientists and engineers in mind. ResearchGATE claims to be the "leading professional network for scientists" [15] and is open to all. Labmeeting [16] caters primarily to biomedical researchers, including researchers in bioengineering and biomaterials, whereas the Engineering Network, "the dedicated network for engineers," [17] is aimed exclusively at engineers, although anyone can join. Each one of these social network sites allows users to create a profile, develop a social network of contacts by searching for other members by name, institution, research interests, etc., and create and/or join interest groups. All three have email features for sending messages to individuals or groups. Users of ResearchGATE and Engineering Network can also create and follow personal blogs.

The various features reflect the kinds of activity users engage in. While ResearchGATE and Labmeeting allow users to upload and share research papers, Engineering Network allows users to upload videos and images and participate in online chat. These differences in features suggest that some social network sites are more concerned with research while others are more concerned with socializing. 
To date, there is limited critical evaluation of these tools, and certainly no one has looked at them within the context of information literacy. The kind of information available in these social network sites has implications for information literacy because the classification of information changes how users retrieve, evaluate and manage the information they find.

\subsection{Organization of information}

The characteristic of information in social network sites that differs from its classification in more traditional sources is that it is bottom-up rather than top-down. It is not hierarchical as it is in traditional sources such as the Library of Congress classification system. Information in the social network site resides within email correspondence, chat transcripts, group discussions, uploaded papers, annotations to uploaded papers, etc. ResearchGATE, in particular, provides blogs, forums and instant messaging to connect researchers. This structure forces users to understand that information is available in different formats at different times and changes as per their information need. Users need enhanced skills to locate information in this environment, as well as the skills to evaluate and manage the information, all of which is needed for lifelong learning. Social network sites provide a one-stop platform to facilitate these different kinds of communication practices, but also give users (if they are aware) a way to find their way through these various paths to information. They are only useful, however, if users have the skills and awareness to make best use of them.

Some ways that social network sites can facilitate organization of information include alerting their members to relevant information in their areas of interest and structuring the information thematically. Labmeeting allows users to be alerted when new papers of interest are added and both Labmeeting and ResearchGATE enable users to recommend papers to others. Engineering Network provides forums by topic where users can discuss issues of relevance to specific fields such as Aerospace or Geological Engineering. ResearchGATE also provides interest groups such as Intelligent Software Engineering and Tissue Engineering as a way of organizing and locating relevant information, as well as a means for connecting with users who share similar interests. Both the structure of these sites and the contributions of its users enable information to be organized from the bottom-up.

\subsection{Evaluation of information}

Social network sites create challenges in terms of the reliability of information but they also facilitate the evaluation of information through the development of communities of trust. Information comes from multiple sources of various levels of expertise and reliability and not from a hierarchical, top-down structure of expert to practitioner to novice. However, several sites offer features that help the user to judge the quality, accuracy, currency, and relevance of the information they find, a key component in being information literate.

Not all social network sites are created equal and the quality of information found in each differs greatly. A quick search through the various directories of engineers in Engineering Network, for example, shows very few members. It is also questionable whether or not these members are, in fact, real engineers.

ResearchGATE is one example of a more sophisticated site which supports cv and publication uploading thus allowing members to verify the credibility of others. Labmeeting limits its members to those from a select list of academic institutions ensuring, to some extent, the reliability of information found on the site.

However, even in social network sites that offer tools to assist with determining the credibility of their members, information provided by members is of varying quality - credibility is not measured by a cv alone. This is the Wikipedia crisis - can you trust information from the collective users who may or may not qualify as experts in their field? Facts, points of view and opinion easily blend in this networked environment. For these reasons, skills relating to evaluating information are especially crucial when using these sites.

One way users can evaluate the information they find is by creating their own communities of trust adding users, building relationships and learning over time who they determine to be trustworthy. Developing research "colleagues" as they are known in Labmeeting replicates the kinds of relationships peers have offline and helps users build these communities of trust with some degree of confidence. This is how the socializing and research features of these sites come together. Users are able to build communities of trust that allow them to develop ongoing relationships where they can share highly relevant information in a fast and convenient way, a tool that may not be available as easily elsewhere. These tools compare favourably with traditional methods of scholarly communication such as conferences, which only take place periodically, and the peer-reviewed process, which is labor-intensive. Social network sites allow users to maintain an 
ongoing relationship with colleagues, which facilitates both timely information dissemination and collaboration.

This circle of trust also extends to publications. In Labmeeting, for example, researchers can refer papers to each other. In ResearchGATE, users can mark papers with "I like this" (and the thumbs up sign). Labmeeting even allows users to add notes to papers with keywords and evaluative qualities for others to see. The Engineering Network has a feature called "sticky comments" where tags can be added to conversation threads, images, videos, etc. These features enable users to evaluate the information they find in social network sites and form communities of trust based on shared interests, which can facilitate the acquisition of reliable information in a fast and efficient way.

\subsection{Management of information}

Information in social network sites is dispersed and divided. Scattered across multiple sources, published in various formats, accessible through different paths and channels, there is no one hierarchical structure providing a top-down approach to expert knowledge or research. The information literate engineer is one who recognizes the importance of extracting, recording, transferring and managing information, and its sources, regardless of its format, and who can manage new information from various sources [12], certainly a challenge in the world of social network sites.

Yet, social network sites also provide users with a platform for managing these various information sources in a single customizable interface. Publication searches through reputable databases such as IEEE, NASA and PubMed are possible from within the single platform of ResearchGATE, for example. Users can conduct literature searches, participate in forums, view RSS feeds, create bookmarks, all within the same interface.

Social network sites designed with research in mind have also created powerful tools for seamless sharing between users and bibliographic management software like EndNote and Reference Manager. In ResearchGATE, users can create their own libraries and easily export references to existing libraries in other bibliographic management tools.

What these networks are not as strong in, is the management of content. ResearchGATE allows users to send annotations to their research contacts. Users of Labmeeting can add notes to a paper and send them to colleagues both within and outside of the site. However, tools that would allow users to create links from research data to discussions to evaluations and to other related content would be very useful for sites to develop.

One significant criticism of all these sites is the lack of awareness - among the administrators and users - of copyright issues around access to information. Issues that emerge from the management of information are quite varied and topical, especially in light of the current changes to copyright law in Canada. Standard Four states that "the information literate student understands the economic, ethical, legal and social issues surrounding the use of information and its technologies" [12] yet some features of social network sites appear to allow questionable use of information. Labmeeting, for instance, allows users to upload pdfs of journal articles without mentioning copyright issues surrounding published documents whereas Engineering Network allows users to upload videos, pictures, blogs, etc. The onus is on users to ensure that they have considered the ethical and legal implications of uploading certain documents and they are not violating copyright law.

Other sites such as ResearchGATE acknowledge copyright laws and include information about self archiving restrictions from publishers for articles posted by individual authors. In cases where publications are not included in ResearchGATE, users may request the full-text of the publication in the hope that the author may be able to provide a copy which does not violate copyright restrictions. This will be for the author to determine in communication with the publisher. ResearchGATE encourages users to add their requests and authors to provide a copy when possible. It states: "Are you the author? Add yourself as author, check your self-archiving restrictions and provide a full-text paper." The usability of these sites might be questionable if members cannot post research articles due to copyright restrictions. Dealing with issues related to copyright on these sites is a problem that will have to be negotiated in the future. Social network sites vary greatly in their awareness and compliance with ethical and legal use of information.

\section{The Role of the Educator}

Much of the literature on the importance of information literacy comes from the academic scholarship of librarians and may be unfamiliar to engineers [18]. Some engineering educators are embracing the need to promote and improve information literacy outcomes, and librarian-faculty collaborations are growing in popularity [19], but the question of whose responsibility it is to teach information literacy skills is open to debate. The 
ACRL standards reflect a concern for the holistic education of the professional-to-be and suggest that the librarian and teaching faculty are both responsible for ensuring that information literacy competencies of engineering students are achieved. Because social network sites combine the information-retrieval process that is traditionally the domain of the librarian with the subject-area expertise of engineering faculty, both librarians and teaching faculty have a role to play in familiarizing students with these tools.

The role of the librarian is distinct from the role of engineering faculty in that the librarian's role has traditionally been one of gathering and preserving information. Librarians have a long history of evaluating sources for their reliability, and social network sites are another such source of information, albeit a rich and multifaceted type of source. Librarians could be involved in assessing and recommending social network sites to both faculty and students. One example of a library that describes different social network sites for science and technology is the Bernard Becker Medical Library at the Washington University in St. Louis School of Medicine [20], which outlines various sites and the functionalities they offer. Librarians can help both students and faculty with understanding how to receive relevant information (for example, by setting up RSS feeds in ResearchGATE); how to evaluate information (by judging various social network sites for quality, accuracy, currency, and relevance of information); and how to manage information (for example, by learning how to import references into users' existing bibliographic management software such as Endnote). Librarians are also well-positioned to familiarize students with copyright issues related to information use within social network sites.

Engineering faculty could focus on the information contained in these sites and issues related to networking and research collaboration within the field. Because of their familiarity with traditional ways of forming communities of trust (through participation in conferences and the peer-review process used for publishing), they are well-positioned to educate students about advantages of online social network sites for research purposes.

\section{Conclusions}

Social network sites are powerful tools for enabling engineers to continue on the path to lifelong learning, helping them to rapidly identify potential collaborators and experts in their field, solve specific problems and build networks of like-minded individuals. However, as every engineer knows: a tool is only as good as the craftsman who uses it. Social networking technologies have made the flow of information more fluid, changing the direction of information from a top-down to a bottom-up classification system. These changes to the nature of the information users are accessing increase the need for higher-level evaluation and analysis skills.

It is important to note that social network sites in their current state are just over five years old. In this context, the quantity of research about them is significant, but still very much in its infancy. As Web 2.0 moves to Web 3.0 and more social network sites develop around specific communities becoming an ingrained part of professional activities, the need to analyse the skills necessary to use these tools successfully will become an important topic not just for researchers, but for practitioners inside and outside the academic environment.

\section{References}

[1] M. A. Robinson, "An empirical analysis of engineers' information behaviors," Journal of the American Society for Information Science and Technology, vol. 61, pp. 640-658, 2010.

[2] J. Wilson, "Social networking: the business case," Engineering \& Technology, vol. 4, pp. 54-56, 2009.

[3] L. Gordon, "Let's get SOCIAL," Machine Design, vol. 81, pp. 50-53, 2009.

[4] W. A. Warr, "Social software: fun and games, or business tools?," Journal of Information Science, vol. 34, pp. 591-604, August 1, 2008.

[5] K. Jones, "Connecting Social Technologies with Information Literacy," Journal of Web Librarianship, vol. 1, pp. 67-80, 2007.

[6] L. Luo, "Web 2.0 Integration in Information Literacy Instruction: An Overview," Journal of Academic Librarianship, vol. 36, pp. 32-40, 2010.

[7] K. Aydelott, "Using the ACRL Information Literacy Competency Standards for Science and Engineering/Technology to Develop a Modular Critical-Thinking-Based Information Literacy Tutorial," Science \& Technology Libraries, vol. 27, pp. 19 - 42, 2007.

[8] T. E. Pinelli, "Distinguishing Engineers from Scientists-The Case for an Engineering Knowledge 
Community," Science \& Technology Libraries, vol. 21, pp. 131 - 163, 2001.

[9] M. Hertzum, "The importance of trust in software engineers' assessment and choice of information sources," Information and Organization, vol. 12, pp. 1-18, 2002.

[10] American Library Association. (Accessed May 16, 2010). Information Literacy Competency Standards for Higher Education. Available: http://www.ala.org/ala/mgrps/divs/acrl/standards/infor mationliteracycompetency.cfm

[11] American Library Association. (Accessed May 16, 2010). Presidential Committee on Information Literacy. Available: http://www.ala.org/ala/mgrps/divs/acrl/publications/w $\underline{\text { hitepapers/presidential.cfm }}$

[12] American Library Association. (Accessed May 16, 2010). Information Literacy Standards for Science and Technology. Available: http://www.ala.org/ala/mgrps/divs/acrl/standards/infoli tscitech.cfm

[13] R. Reichardt, "How May I Help Thee? Let Me Count the 2.0 Ways...," Internet Reference Services Quarterly, vol. 13, pp. 271 - 280, 2008.
[14] C. Madge, et al., "Facebook, social integration and informal learning at university: 'It is more for socialising and talking to friends about work than for actually doing work'," Learning, Media and Technology, vol. 34, pp. 141 - 155, 2009.

[15] ResearchGATE. (Accessed May 16, 2010). Available: http://www.researchgate.net/

[16] Labmeeting. (Accessed May 16, 2010). Available: http://www.labmeeting.com/

[17] Engineering Network. (Accessed May 16, 2010). Available: http://www.engineering-network.net/

[18] S. Keilson and S. Cooperstein, "Work in progress - information literacy, plagiarism and engineering education," in Frontiers In Education Conference Global Engineering: Knowledge Without Borders, Opportunities Without Passports, 2007. FIE '07. 37th Annual, 2007, pp. T3B-15-T3B-16.

[19] P. Montiel-Overall, "Research on teacher and librarian collaboration: An examination of underlying structures of models," Library \& Information Science Research, vol. 29, pp. 277-292, 2007.

[20] Bernard Becker Medical Library. (Accessed May 16, 2010). Social Network Sites for the Sciences and Technology. Available: http://www.becker.wustl.edu/services/socialnetw.html 